\title{
Regulation of adiposity by mTORC1
}

\section{Controle da adiposidade por mTORC1}

\author{
Juliana Magdalon $^{1}$, William Tadeu Festuccia ${ }^{2}$
}

\begin{abstract}
Obesity is characterized by an excessive increase in the adipose tissue mass, and is associated with higher incidence of several chronic metabolic diseases, such as type 2 diabetes. Therefore, its increasing prevalence is a public health concern, and it is important to better understand its etiology to develop new therapeutic strategies. Evidence accumulated over the years indicates that obesity is associated with a marked activation in adipose tissue of the mechanistic target of rapamycin complex 1 (mTORC1), a signaling pathway that controls lipid metabolism, and adipocyte formation and maintenance. Curiously, mTORC1 is also involved in the control of nonshivering thermogenesis and recruitment as well as browning of white adipose tissue. In this review, we explored mTORC1 functions in adipocytes and presented evidence, suggesting that mTORC1 may either increase or reduce adiposity, depending on the conditions and activation levels.
\end{abstract}

Keywords: Obesity; Adiposity; Adipocytes; Lipids; Thermogenesis

\section{RESUMO}

A obesidade é caracterizada pelo aumento excessivo da massa de tecido adiposo, estando associada à maior incidência de diversas doenças metabólicas crônicas, como diabetes tipo 2. Sua crescente prevalência é uma questão de saúde pública, e faz-se importante compreender melhor sua etiologia, para desenvolver novas estratégias terapêuticas. As evidências acumuladas por muitos anos indicam que a obesidade está associada à significativa ativação no tecido adiposo do complexo 1 da proteína alvo mecanístico da rapamicina (mTORC1), uma via de sinalização que regula o metabolismo de lipídeos, bem como a formação e manutenção de adipócitos. Curiosamente, mTORC1 também está envolvido no controle da termogênese, independente do tremor muscular, e no recrutamento e browning de tecido adiposo branco. Nesta revisão, exploramos as diferentes funções do mTORC1 em adipócitos e apresentamos evidências que sugerem que o mTORC1 pode aumentar ou reduzir a adiposidade, dependendo das condições e de seu nível de ativação.

Descritores: Obesidade; Adiposidade; Adipócitos; Lipídeos; Termogênese

\section{INTRODUCTION}

Obesity is the excessive accumulation of fat in adipose tissue and ectopically in other organs, such as in the liver, resulting from chronic periods of positive energy balance, characterized by energy intake higher than energy expenditure. Clinically, patients are considered obese after reaching a body mass index (BMI) equal or higher than $30 \mathrm{~kg} / \mathrm{m}^{2}$. The prevalence of obesity has dramatically increased in the last decades attaining levels of a global pandemic, ${ }^{(1)}$ such a worrisome event that has been mainly attributed to the current lifestyle characterized by unhealthy dietary habits and sedentary behavior. A major concern for public health is the fact that obesity is frequently associated with the development of several chronic diseases, such as type 2 diabetes, ${ }^{(2)}$ cardiovascular diseases, ${ }^{(3)}$ hepatic steatosis ${ }^{(4)}$ and some types of cancer. ${ }^{(5)}$ Importantly, despite being an important risk factor to metabolic disorders, not all obese people develop those diseases. Indeed, obese patients that accumulate fat preferentially in the visceral adipose depots located inside the peritoneal cavity have a much higher chance of developing metabolic disorders than those that accumulate fat in subcutaneous adipose depots. ${ }^{(6)}$ Such a phenomenon has been related to the higher spillover of lipids, lipotoxicity and inflammatory

\footnotetext{
Hospital Israelita Albert Einstein, São Paulo, SP, Brazil.

2 Universidade de São Paulo, São Paulo, SP, Brazil.

Corresponding author: Juliana Magdalon - Avenida Albert Einstein, 627/701 - Morumbi - Zip code: 05652-000 - São Paulo, SP, Brazil - Phone: (55 11) 96787-1517 - E-mail: juliana.magdalon@einstein.br Received on: Apr 30, 2017 - Accepted on: Sep 20, 2017

DOI: 10.1590/S1679-45082017RB4106
} 
process associated with visceral, but not subcutaneous obesity.

\section{Types of adipocytes and factors driving adipose tissue enlargement}

Three different types of adipocytes can be found in humans: white adipocytes, the main cells composing white adipose tissue (WAT), that exert lipid storage and endocrine functions; brown adipocytes, the main cells composing brown adipose tissue (BAT), whose main function is to produce heat through mitochondrial uncoupling protein 1 (UCP-1)-dependent nonshivering thermogenesis; and beige adipocytes, which are located in white adipose depots and, depending on the condition, may act either as white (lipid storage) or brown (UCP-1induced heat production) adipocytes (Figure 1). ${ }^{(7)}$

Excessive fat accumulation and adipose tissue enlargement generally result from a combination of increase in both white adipocyte diameter (hypertrophy) and number (hyperplasia). While the former is determined by cell content of triacylglycerol (TAG), which reflects the balance between lipolysis (triacylglycerol hydrolysis) and lipogenesis (triacylglycerol synthesis), the latter reflects the equilibrium between cell formation, which involves the proliferation, commitment and differentiation of adipose tissue-resident mesenchymal cells into mature adipocytes, and adipocyte apoptosis.

Over the years, some studies have shown strong evidence that the mechanistic target of rapamycin complex 1 (mTORC1) is an important regulator of adipose tissue formation and lipid storage function. Indeed, mTORC1 has been implicated in the regulation of early adipocyte precursor commitment, preadipocyte differentiation into mature adipocytes (adipogenesis), as well as TAG synthesis and mobilization in adipocytes. ${ }^{(8)}$ Moreover, the activity of mTORC1 was consistently shown to be increased in adipose tissue of genetically and high fat diet-induced obese mice, ${ }^{(9)}$ indicating a likely involvement of this complex in adipose tissue enlargement. In addition to its role in white fat, recent studies have also shown that mTORC1 is involved in the regulation of BAT thermogenesis and beige cells recruitment and activation (browning). Herein, we reviewed the major findings of those studies and propose a model of adiposity regulation by mTORC1.

\section{mTORC1 biology}

mTORC1 is composed of several proteins in addition to the serine/threonine kinase mTOR: regulatory-associated protein of mTOR (Raptor), mammalian lethal with SEC13 protein 8 (mLST8), proline-rich AKT substrate of 40kDa (PRAS40) and DEP domain-containing mTORinteracting protein (DEPTOR). mTORC1 plays a key role in the regulation of cell metabolism and homeostasis. When activated, mTORC1 promotes anabolic processes, such as protein, nucleotide and lipid syntheses, and inhibits catabolic processes, such as autophagy, through the phosphorylation of several proteins, including S6 kinases (S6Ks), eukaryotic initiation factor 4E (eIF4E)-binding proteins (4E-BPs) and unc-51 like autophagy activating kinase 1 (ULK-1), among others. mTORC1 is mainly activated by amino acids through a process mediated by proteins denominated Rags, which involves complex translocation from the cytosol to the lysosomes. ${ }^{(10)}$ In addition to amino acids, mTORC1 is also activated by growth factors such as insulin, through the canonical
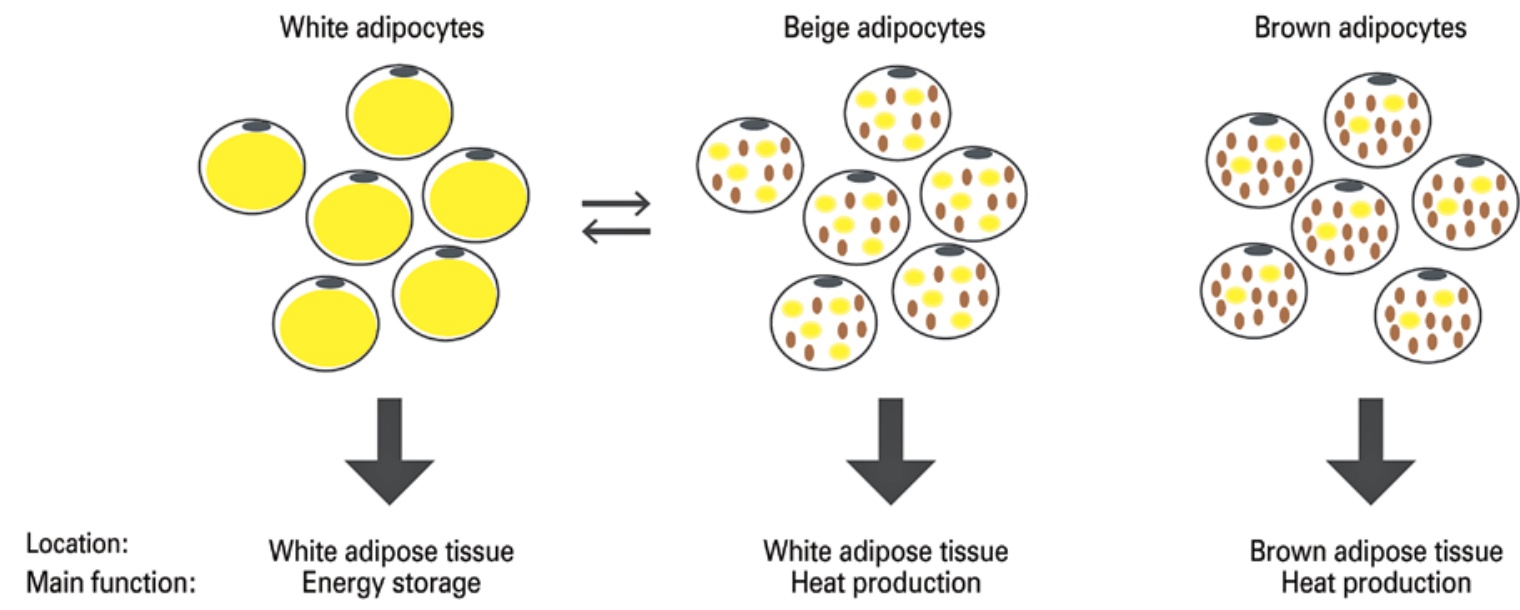

Yellow spots: lipid droplets; brown spots: mitochondria; black spots: nuclei.

Figure 1. Differences among white, beige and brown adipocytes in relation to location and main function 
IRS-PI3K-AKT signaling pathway. Upon its activation, AKT phosphorylates and inhibits the tuberous sclerosis complex (TSC), which is a GTPase-activating protein (GAP) toward Ras homolog enriched in brain (RHEB). When TSC is inhibited and, consequently, RHEB is bound to GTP, it stimulates mTORC1 recruitment to the lysosome membrane, where it is activated in the presence of amino acids (Figure 2)..$^{(11)}$

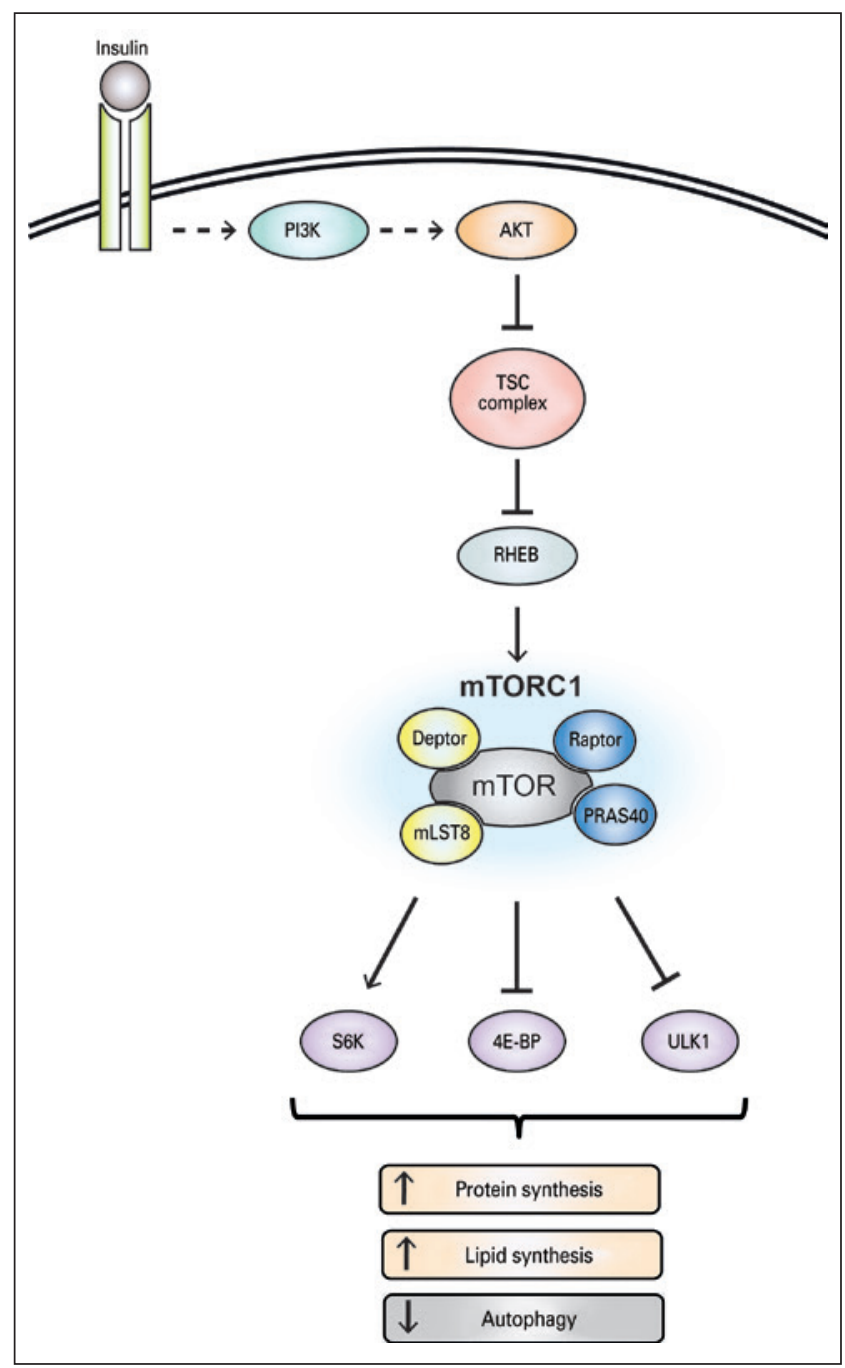

Figure 2. Overview of mechanistic target of rapamycin complex 1 signaling pathway and function (mTOR)

\section{mTORC1 loss-of-function and adiposity}

The first evidence indicating that mTORC1 plays an important role in the regulation of adiposity came out from in vitro studies showing that pharmacological inhibition of mTORC1 with rapamycin completely blocks the ability of 3T3-L1 cells to differentiate into mature adipocytes. These effects were attributed to a reduced expression of peroxisome proliferator-activated receptor (PPAR) $\gamma$ and CCAAT-enhancer-binding protein $(\mathrm{C} / \mathrm{EBP}) \alpha$, which are major transcription factors required for adipogenesis. ${ }^{(12-15)}$ Besides these in vitro findings, the administration of rapamycin to rodents in vivo was associated with a reduction in adiposity due to lower expression of PPAR $\gamma$ and target genes involved in lipid uptake and storage ${ }^{(16)}$ and a protection against the fat mass expansion and obesity induced by the intake of a high-fat diet. ${ }^{(17)}$

Genetically modified mice displaying whole-body or tissue specific (Cre-lox) deficiencies of mTORC1 essential component Raptor, or of the downstream substrate $S 6 k$ were also employed to investigate mTORC1 involvement in the regulation of adiposity. Corroborating studies with rapamycin, mice with whole-body deficiency of $S 6 \mathrm{k} 1$ displayed reduced fat mass, and were protected against diet-induced obesity; ${ }^{(9)}$ such phenotypes were attributed to impaired adipogenesis. ${ }^{(18)}$ Nonetheless, a similar reduction in adiposity and protection against obesity was also seen in mice with Raptor deletion in adipocytes. ${ }^{(19,20)}$ Conflicting molecular mechanisms were provided to explain those phenotypes, i.e., either enhanced energy expenditure as a result of adipocyte browning, ${ }^{(19)}$ or a defect in adipose tissue expansion due to impaired $\mathrm{C} / \mathrm{EBP} \alpha$ expression. ${ }^{(20)}$ The above differences, however, likely reflect the use of distinct Fabp4 (ap2) and adiponectin promoters to drive Cre recombinase expression, with the former showing a much lower adipocyte specificity than the latter. ${ }^{(21)}$ Finally, mice with deficiency of both mTORC1 and 2 in adipocytes due to the adiponectin-cre drive deletion of $m T O R$ have also reduced adiposity, which was associated with adipocyte browning and impaired adipogenesis as a result of reduced PPAR $\gamma$ and $\mathrm{C} / \mathrm{EBP} \alpha$ expression. ${ }^{(22)}$ Therefore, it is possible to conclude that mTORC1 deficiency or complete inhibition in adipocytes leads to impaired adipogenesis and lipid deposition, enhanced adipocyte browning and reduced adiposity.

\section{mTORC1 partial inhibition and adiposity}

In sharp contrast to the impaired adipogenesis and reduction in adiposity induced by adipocyte mTORC1 deficiency or pharmacological inhibition, partial inhibition of this complex was shown to enhanced adipogenesis and increase adiposity. Indeed, partial knockdown of mTOR with a shRNA potentiates the differentiation of 3T3-L1 preadipocytes into mature adipocytes in vitro, as evidenced by the higher accumulation of TAG. ${ }^{(23)}$ Furthermore, partial inhibition of mTORC1 activity in vitro and in vivo through the overexpression of 
Deptor, an endogenous inhibitor of mTORC1, enhanced adipogenesis and exacerbated increase in body weight and WAT mass induced by the intake of a high-fat diet. ${ }^{(24)}$ On the mechanistic level, such enhanced adipogenesis and increased adiposity induced by partial mTORC1 inhibition were attributed to the dampening of the negative feedback upon IRS function and intracellular insulin signaling exerted by mTORC1/S6K1, which then enhanced the PI3K-AKT-PPAR $\gamma$ pathway and, consequently, the adipogenesis and lipogenesis. ${ }^{(24)}$ Therefore, partial mTORC1 inhibition promotes adipogenesis and adipose tissue expansion.

\section{mTORC1 gain-of-function and adiposity}

Our group was the first to characterize the effect of adipocyte constitutive mTORC1 activation on adiposity and body weight in vivo. Indeed, mice with constitutive mTORC1 activation in adipocytes displayed a depotspecific reduction in the mass of visceral adipose tissue (retroperitoneal depot), in association with increased browning (UCP-1 content), lipolysis, mitochondrial mass and oxidative activity. ${ }^{(25)}$ In contrast to those findings, however, constitutive mTORC1 activation in adipocytes using the nonadipocyte-specific Fabp 4 Cre mice reported no alteration in WAT mass in 2-day-old mice. ${ }^{(26)}$ It is worth mentioning that older mice were not evaluated in this study since the animals died within 48 hours after birth, probably due to Tsc1 deletion in cells other than adipocytes, mediated by non-specific Cre expression. ${ }^{(26)}$ Based on those findings, one may conclude that constitutive mTORC1 activation in adipocytes reduces visceral adiposity.

\section{Proposed model of adiposity regulation by mTORC1}

Based on the above-detailed studies describing the changes in adiposity associated with mTORC1 loss-offunction, partial inhibition, and constitutive activation, we and other authors ${ }^{(27)}$ have proposed that mTORC1 regulation of adiposity follows an inverted U-shaped curve, in which optimal levels of mTORC1 activity - neither too low as induced by Raptor deletion and rapamycin treatment, not too high as that induced by Tsc1 deletion - are required for this complex to promote its pro-adipogenic and lipogenic actions (Figure 3). Such optimal level of mTORC1 activity could respond for the lipid accretion and exacerbated adiposity found upon obesity and Deptor overexpression, for example. Studies evaluating the effects of different levels of mTORC1 activity upon adiposity in a unique experiment setting, however, are still required to confirm this proposed model.

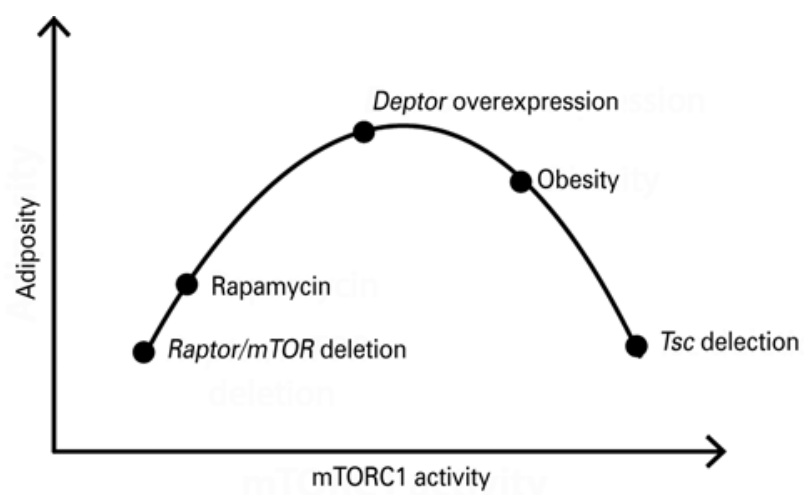

Figure 3. Association between mechanistic target of rapamycin complex 1 (mTORC1) activity and adiposity in different animal models

\section{mTORC1 and nonshivering thermogenesis}

In addition to its role in the regulation of adiposity, mTORC1 was also shown to be necessary for BAT thermogenic function and WAT browning induced by $\beta 3$-adrenergic stimulation or cold exposure. ${ }^{(28-30)}$ More specifically, mTORC1 is activated in BAT and WAT in response to cold, and $\beta$-adrenergic stimulation through a mechanism that seems to involve a $\beta$-adrenergic receptor-mediated increase in cAMP and activation of protein kinase A (PKA), which in turn phosphorylates Raptor and mTOR, increasing complex activity. Moreover, in both BAT and visceral WAT, mTORC1 was shown to regulate mitochondrial biogenesis, oxidative metabolism and UCP-1 expression. ${ }^{(25,28)}$ Altogether, these findings establish mTORC1 as an important regulator of nonshivering thermogenesis in both BAT and beige cells.

\section{CONCLUSION}

Obesity is a current concern worldwide due to its increasing prevalence and strong association with several metabolic diseases. Unfortunately, up to date, no effective treatment has been established to counteract the development of these diseases. mTORC1 signaling is activated in adipose tissue upon obesity and participates in the enhanced lipid deposition and adipose tissue expansion found in this condition. Understanding the mechanisms by which different levels of mTORC1 activity regulate adiposity may enable the development of strategies to efficiently counteract adipose tissue enlargement and obesity.

\section{REFERENCES}

1. Swinburn BA, Sacks G, Hall KD, McPherson K, Finegood DT, Moodie ML, et al. The global obesity pandemic: shaped by global drivers and local environments. Lancet. 2011;378(9793):804-14. 
2. Niswender K. Diabetes and obesity: therapeutic targeting and risk reduction a complex interplay. Diabetes Obes Metab. 2010;12(4):267-87. Review.

3. Zalesin KC, Franklin BA, Miller WM, Peterson ED, McCullough PA. Impact of obesity on cardiovascular disease. Endocrinol Metab Clin North Am. 2008; 37(3):663-84, ix. Review.

4. Marchesini G, Moscatiello S, Di Domizio S, Forlani G. Obesity-associated liver disease. J Clin Endocrinol Metab. 2008;93(11 Suppl 1):S74-80. Review.

5. Roberts DL, Dive C, Renehan AG. Biological mechanisms linking obesity and cancer risk: new perspectives. Annu Rev Med. 2010;61:301-16. Review.

6. Després JP, Lemieux I. Abdominal obesity and metabolic syndrome. Nature. 2006:444(7121):881-7. Review.

7. Rosen ED, Spiegelman BM. What we talk about when we talk about fat. Cell. 2014;156(1-2):20-44. Review.

8. Ricoult SJ, Manning BD. The multifaceted role of mTORC1 in the control of lipid metabolism. EMBO Rep. 2013;14(3):242-51. Review.

9. Um SH, Frigerio F, Watanabe M, Picard F, Joaquin M, Sticker M, et al. Absence of S6K1 protects against age- and diet-induced obesity while enhancing insulin sensitivity. Nature. 2004;431(7005):200-5. Erratum in: Nature. 2004; 431 (7007):485.

10. Bar-Peled L, Sabatini DM. Regulation of mTORC1 by amino acids. Trends Cell Biol. 2014;24(7):400-6. Review.

11. Menon S, Dibble CC, Talbott G, Hoxhaj G, Valvezan AJ, Takahashi H, et al. Spatial control of the TSC complex integrates insulin and nutrient regulation of mTORC1 at the lysosome. Cell. 2014;156(4):771-85.

12. Yeh WC, Bierer BE, McKnight SL. Rapamycin inhibits clonal expansion and adipogenic differentiation of 3T3-L1 cells. Proc Natl Acad Sci U S A. 1995; 92(24):11086-90.

13. Gagnon A, Lau S, Sorisky A. Rapamycin-sensitive phase of 3T3-L1 preadipocyte differentiation after clonal expansion. J Cell Physiol. 2001;189(1):14-22

14. Cho HJ, Park J, Lee HW, Lee YS, Kim JB. Regulation of adipocyte differentiation and insulin action with rapamycin. Biochem Biophys Res Commun. 2004; 321(4):942-8

15. Kim JE, Chen J. Regulation of peroxisome proliferator-activated receptorgamma activity by mammalian target of rapamycin and amino acids in adipogenesis. Diabetes. 2004;53(11):2748-56.

16. Houde VP, Brûlé S, Festuccia WT, Blanchard PG, Bellmann K, Deshaies Y, et al. Chronic rapamycin treatment causes glucose intolerance and hyperlipidemia by upregulating hepatic gluconeogenesis and impairing lipid deposition in adipose tissue. Diabetes. 2010;59(6):1338-48.

17. Chang GR, Chiu YS, Wu YY, Chen WY, Liao JW, Chao TH, et al. Rapamycin protects against high fat diet-induced obesity in C57BL/6J mice. J Pharmacol Sci. 2009:109(4):496-503
18. Carnevalli LS, Masuda K, Frigerio F, Le Bacquer 0, Um SH, Gandin V, et al S6K1 plays a critical role in early adipocyte differentiation. Dev Cell. 2010; 18(5):763-74.

19. Polak P, Cybulski N, Feige JN, Auwerx J, Rüegg MA, Hall MN. Adipose-specific knockout of raptor results in lean mice with enhanced mitochondrial respiration. Cell Metab. 2008;8(5):399-410.

20. Lee PL, Tang Y, Li H, Guertin DA. Raptor/mTORC1 loss in adipocytes causes progressive lipodystrophy and fatty liver disease. Mol Metab. 2016;5(6): 422-32.

21. Lee KY, Russell SJ, Ussar S, Boucher J, Vernochet C, Mori MA, et al. Lessons on conditional gene targeting in mouse adipose tissue. Diabetes. 2013; 62(3):864-74.

22. Shan T, Zhang P, Jiang 0 , Xiong Y, Wang Y, Kuang S. Adipocyte-specific deletion of mTOR inhibits adipose tissue development and causes insulin resistance in mice. Diabetologia. 2016;59(9):1995-2004.

23. Yoon MS, Zhang C, Sun Y, Schoenherr CJ, Chen J. Mechanistic target of rapamycin controls homeostasis of adipogenesis. J Lipid Res. 2013;54(8): 2166-73.

24. Laplante M, Horvat S, Festuccia WT, Birsoy K, Prevorsek Z, Efeyan A, et al. DEPTOR cell-autonomously promotes adipogenesis, and its expression is associated with obesity. Cell Metab. 2012;16(2):202-12.

25. Magdalon J, Chimin P, Belchior T, Neves RX, Vieira-Lara MA, Andrade ML, et al. Constitutive adipocyte mTORC1 activation enhances mitochondria activity and reduces visceral adiposity in mice. Biochim Biophys Acta. 2016; 1861(5):430-8

26. Xiang X, Lan H, Tang H, Yuan F, Xu Y, Zhao J, et al. Tuberous sclerosis complex 1-mechanistic target of rapamycin complex 1 signaling determines brown-towhite adipocyte phenotypic switch. Diabetes. 2015;64(2):519-28.

27. Caron A, Richard D, Laplante M. The roles of mTOR complexes in lipid metabolism. Annu Rev Nutr. 2015;35:321-48.

28. Labbé SM, Mouchiroud M, Caron A, Secco B, Freinkman E, Lamoureux G, et al. mTORC1 is required for brown adipose tissue recruitment and metabolic adaptation to cold. Sci Rep. 2016;6:37223.

29. Liu D, Bordicchia M, Zhang C, Fang H, Wei W, Li JL, et al. Activation of mTORC1 is essential for $\beta$-adrenergic stimulation of adipose browning. J Clin Invest. 2016;126(5):1704-16

30. Tran CM, Mukherjee S, Ye L, Frederick DW, Kissig M, Davis JG, et al. Rapamycin blocks induction of the thermogenic program in white adipose tissue. Diabetes. 2016;65(4):927-41. 